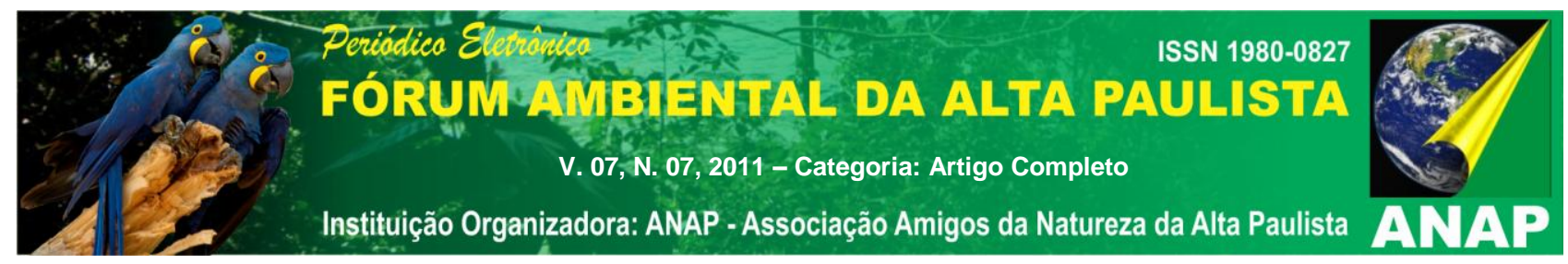

\title{
ELABORAÇÃO DO MÓDULO ASSOCIATIVO E COMUNIDADE COM VISTA AO DESENVOLVIMENTO DE UM SISTEMA INTEGRADO DE GESTÃO AGRícOLA E FLORESTAL(SIG-AF) PARA PEQUENAS PROPRIEDADES RURAIS
}

Thais Alves ${ }^{1}$

Ivo Francisco Barbosa²

Sergio Corrêa Pimenta ${ }^{3}$

Gilson José Silva ${ }^{4}$

Luiz Cesar Ribas ${ }^{5}$

Resumo: No Brasil e no mundo é crescente o interesse pela busca da sustentabilidade dos recursos florestais como base para o desenvolvimento econômico, assim se faz necessária a participação de todos os setores da sociedade, para que deste modo a partir de ações e princípios seja contemplado os escopos social, econômico e ambiental. Aliado a isso, a crescente exigência por produtos de qualidade, onde estão inseridos todos os setores da produção, desde a gestão em relação ao meio ambiente e as condições reais de trabalho, e as dificuldades dos pequenos agricultores em produzir com qualidade e em condições com que seus produtos possam encontrar um cenário propício a comercialização e desse modo, propiciar ganhos socioeconômicos e ambientais. Analisando essas condições tornou-se oportuno a criação de Sistema Integrado de Gestão Agropecuária e Florestal (SIG - AF) que possa servir de base para um

"Graduando em Ciências Biológicas pela Universidade Estadual Paulista "Júlio de Mesquita Filho" (UNESP). Campus de Botucatu/SP, thaisbiobtu@hotmail.com;

${ }^{2}$ Licenciado em Geografia, Pós-graduando em Gestão Ambiental pelo IBEAS/UFSCar, E-mail: ivo francisco@hotmail.com;

${ }^{3}$ Engenheiro Agrônomo, Sócio proprietário da empresa Ecologia Aplicada, E-mail: pimcorrea@gmail.com ;

${ }^{4}$ Engenheiro Florestal. Professor Assistente Doutor junto ao Departamento de Gestão e Tecnologia Agroindustrial, da Faculdade de Ciências Agronômicas, da Universidade Estadual Paulista "Júlio de Mesquita Filho" (UNESP). Campus de Botucatu/SP. E-mail: Icribas@fca.unesp.br;

${ }^{5}$ Administrador de Empresas. Doutor em Energia na Agricultura junto ao Departamento de Engenharia Rural, da Faculdade de Ciências Agronômicas, da Universidade Estadual Paulista "Júlio de Mesquita Filho" (UNESP). E-mail: gilsonjsbtu4@gmail.com. 


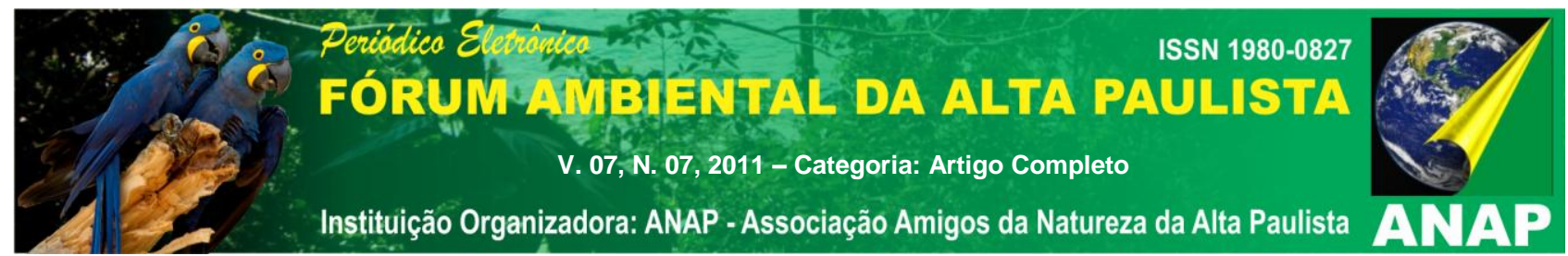

modelo de certificação voltado para o desenvolvimento rural sustentável, e assim subsidiar não só o desenvolvimento rural com também inovação tecnológicas sustentáveis. Sendo assim é necessário o desenvolvimento de um critério de certificação de um módulo associativo para pequenos proprietários rurais que esteja de acordo com as condições econômicas dessas propriedades que por ventura servirem de apoio ao módulo. O presente trabalho trata-se da apresentação do que deve ser o Módulo "Associativismo e Comunidade" no que tange pequenas propriedades rurais com vista a boas práticas agrícolas.

Palavras-chave: Certificação, Agricultura, Sustentabilidade

\section{INTRODUÇÃO}

No Brasil e no mundo é crescente o interesse pela busca da sustentabilidade dos recursos florestais como base para o desenvolvimento econômico, por conta disso empresas, sociedade, governos, dentre outros buscam incorporar e implantar princípios e ações que contemplem os escopos social, econômico e ambiental em suas discussões e atividades.

Somado aos problemas relacionados ao tema, no que tange à proteção ambiental como contrapeso ao desenvolvimento econômico, há uma crescente exigência do consumidor por produtos certificados cujas matérias primas tenham sido produzidas de maneira responsável, do ponto de vista de produção e gestão, em relação ao meio ambiente e à saúde dos trabalhadores ${ }^{6}$.

No setor agropecuário, estas tendências também se aplicam indistintamente do tamanho das propriedades rurais, quer grandes, médias e, mais recentemente, pequenas.

Note-se, dentro do reforço deste último escopo que, em 2001, foi editada pelo Poder Público Federal a Medida Provisória n. $2166-67^{7}$, que traz entre outras, a definição de Pequenas Propriedades Rurais ${ }^{8}$.

\footnotetext{
${ }^{6}$ UTZ. Disponível em: <http//www.utzcertified.org/index.php?pagelD=108>. Acessado em 10 de junho de 2011.

${ }^{7}$ Medida Provisória n. 2.166-7, de 24 de agosto de 2001, que a Altera os arts. $1^{\circ}, 4^{\circ}, 14,16$ e 44, e acresce dispositivos à Lei n- 4.771, de 15 de setembro de 1965, que institui o Código Florestal, bem como altera o art. 10 da Lei $n^{\circ}$ 9.393, de 19 de dezembro de 1996, que dispõe sobre o Imposto sobre a Propriedade Territorial Rural - ITR, e dá outras providências (fonte: http://www.planalto.gov.br/ccivil_03/mpv/216667.htm)
}

${ }^{8}$ Inc. I, do parágrafo 2º, do artigo 1ํ, da MP n. 2.166-67/01. 


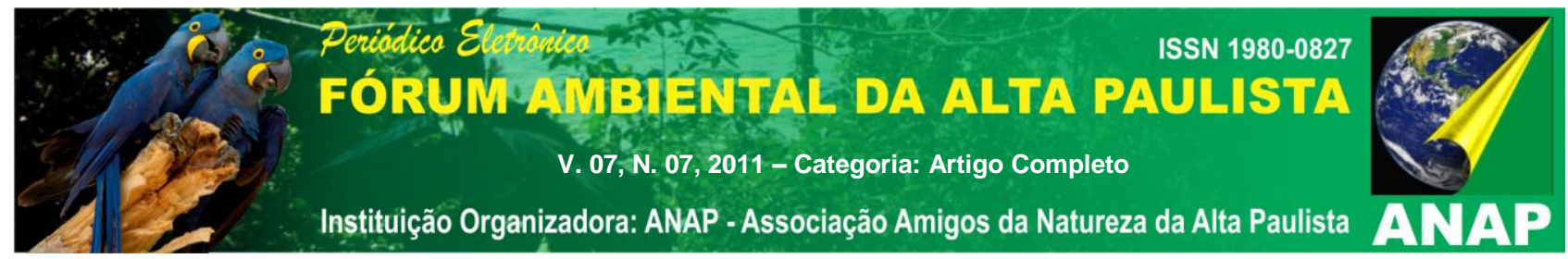

Nos termos da referida Medida Provisória, "pequena propriedade rural ou posse rural familiar" seria "aquela explorada mediante o trabalho pessoal do proprietário ou posseiro e de sua família, admitida a ajuda eventual de terceiro e cuja renda bruta seja proveniente, no mínimo, em oitenta por cento, de atividade agroflorestal ou do extrativismo, cuja área não supere: a) cento e cinquenta hectares se localizada nos Estados do Acre, Pará, Amazonas, Roraima, Rondônia, Amapá e Mato Grosso e nas regiões situadas ao norte do paralelo $13^{\circ} \mathrm{S}$, dos Estados de Tocantins e Goiás, e ao oeste do meridiano de $44^{\circ} \mathrm{W}$, do Estado do Maranhão ou no Pantanal mato-grossense ou sul-mato-grossense; b) cinquenta hectares, se localizada no polígono das secas ou a leste do Meridiano de 44ํㅡ, Wo Estado do Maranhão; e c) trinta hectares, se localizada em qualquer outra região do País.

Esse dispositivo legal em específico representou um marco importante na evolução das políticas públicas de proteção ambiental, sobretudo quando consideramos a importância das pequenas propriedades para a economia nacional.

No entanto, com respeito ao modo de produção e gestão sustentável, há uma grande dificuldade por parte dos pequenos produtores de se encaixar nos critérios de certificação e, consequentemente, de atender às exigências dos consumidores ${ }^{9}$.

Tais dificuldades são, em grande parte, decorrentes dos elevados custos de adesão a determinadas normas e em alguns casos, devido à elevada carga de processos administrativos ${ }^{10}$.

Também deve-se acrescentar que o apoio técnico por parte das certificadoras resume-se a apontar os erros, as desconformidades e as razões da impossibilidade de certificação. Isto, todavia, ainda é insuficiente para que os interessados obtenham as devidas e necessárias instruções para a futura adequação.

Com respeito particularmente ao setor rural da região de Botucatu, a sociedade local (principalmente dentro das relações de consumo), reproduzindo a tendência da sociedade de maneira geral, também está exigindo a prática de uma agricultura em uma base cada vez mais sustentável.

\footnotetext{
${ }^{9}$ GLOBAGAP - SMALLHOLDER INVOLVEMENT. Disponível em: <http://www.globalgap.org/cms/front_content.php?idcat=70> Acesso em 25 de maio de 2011.

${ }^{10}$ LAFORGA, EID; 2005
} 


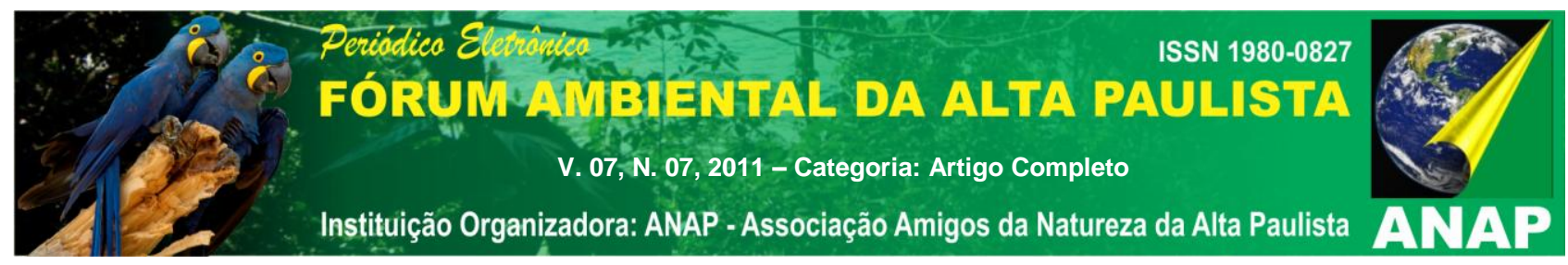

Essas boas práticas agrícolas devem contar com políticas e processos de gestão socioambientais, com novas estruturas de governança corporativa, com novos valores de ética empresarial, bem como, com negócios e produtos elaborados dentro de critérios ambientais, econômicos, sociais e culturais.

Considerando a relação entre a atividade produtiva do setor agropecuário e a sustentabilidade tornou-se oportuno o desenvolvimento de um Sistema Integrado de Gestão Agropecuária e Florestal (SIG-AF) que possa servir de base para um modelo de certificação voltado para o desenvolvimento rural sustentável, promovendo a credibilidade do produto através de seus atributos ambientais, sociais, culturais e econômicos.

Um SIG-AF bem estruturado poderá contribuir para reforçar ganhos administrativos e técnicos das atividades agropecuárias, porem depende, sobejamente dos mecanimos e atributos dos mercados agrícolas.

De toda sorte, um SIG-AF permite, via adequação e certificação das propriedades agrícolas, a participação em mercados agrícolas específicos ou diferenciados.

Por fim, acredita-se que a grande contribuição do SIG-AF seria o estabelecimento de um processo contínuo de inovação tecnológica sustentável.

Como uma das etapas do processo de criação de um SIG-AF, será necessário desenvolver um critério de certificação do módulo associativo que esteja de acordo com as necessidades, capacidades e orçamento das pequenas propriedades rurais.

O trabalho em questão trata-se justamente da apresentação de uma primeira aproximação daquilo que se entende como o desenvolvimento do módulo "Associativismo e Comunidade" como etapa inicial para a criação de um SIG-AF focado, preponderantemente, às pequenas propriedades rurais.

\section{OBJETIVOS}

O objetivo principal desse trabalho foi formular o módulo Associativismo e Comunidade que deve compor uma das diversas etapas do Sistema Integrado de Gestão Agropecuária e Florestal (SIG-AF) voltado para as pequenas propriedades rurais.

Como objetivo secundário, pretende-se desenvolver um módulo ligado aos temas associativismo e comunidade que auxilie o agricultor a recuperar, compreender e aplicar 


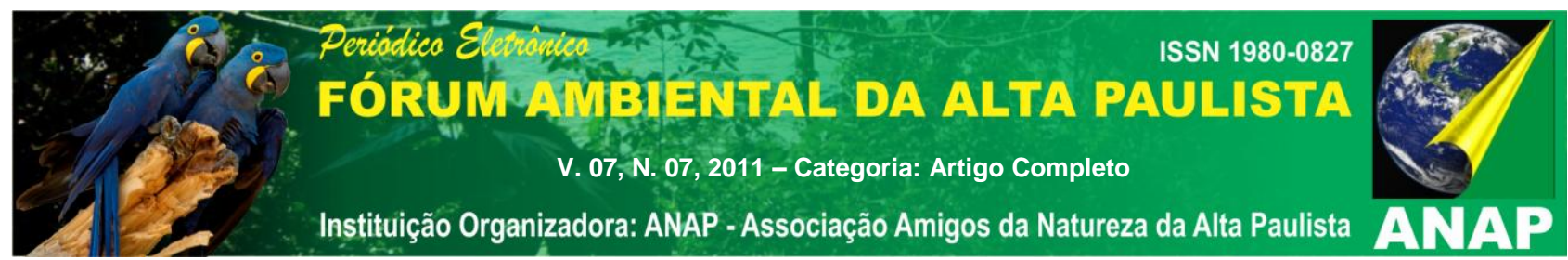

informações para o desenvolvimento e gestão dos sistemas de produção agrícola no contexto dos seus ecossistemas e comunidades e que sirva de base para um modelo de certificação colaborativo.

Para tanto, pretende-se trabalhar junto às associações rurais selecionadas no projeto com os conceitos, dentre outros, de "boas práticas agropecuárias" e "alfabetização ecológica”.

\section{MATERIAL E MÉTODOS}

A partir da análise das principais normas, tanto obrigatórias (leis, decretos e outros instrumentos de comando e controle de base legal) de escopo federal, estadual ou municipal, quanto voluntárias (tais como as normas da família ISO), serão propostas as bases para um novo critério de certificação que sirva como procedimento para a gestão visando a manutenção dos padrões de qualidade para conquista e expansão de mercados, permitindo adotar conceitos e regras para o gerenciamento eficaz dos recursos com responsabilidade e análise crítica periódica.

As normas analisadas e utilizadas como base para o presente trabalho foram GLOBALGAP, UTZ CERTIFIED, FIB, ORGÂNICOS DO BRASIL, FSC, RAINFOREST ALLIANCE e FAIRTRADE.

Tais propostas para certificação foram criadas com a intenção de propiciar ao consumidor um produto de qualidade que gere benefícios socioeconômicos para todos os integrantes dessa temática, em consonância com o meio ambiente ecologicamente equilibrado.

Todavia, cada uma das normas possui origens peculiares, e foi criada para suprir necessidades do mercado ao qual cada uma esta sobreposta, resultando nas características impares das mesmas. Muitas delas apresentam histórias diferentes e origens variadas, no entanto, apresentam muitas semelhanças quanto aos critérios propostos.

A fim de abranger todos os aspectos das normas estudadas como base de estudo e também aqueles cruciais ao bom desempenho do SIG-AF, foi montada uma tabela em 


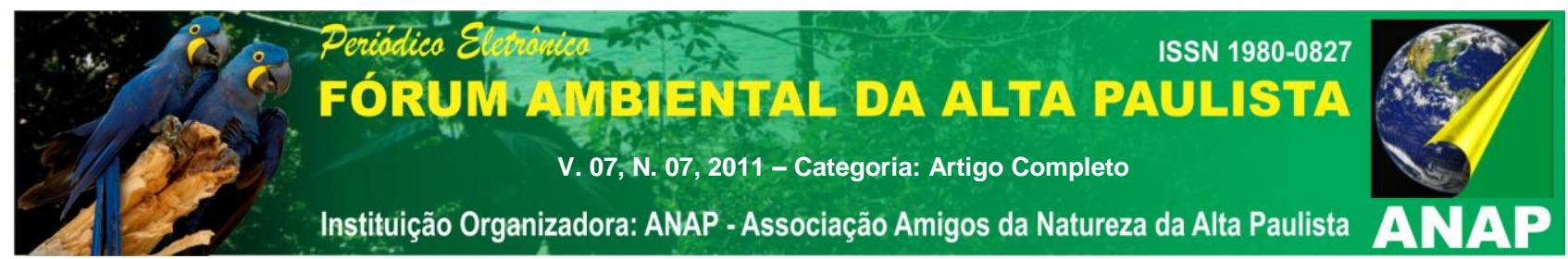

Excel, de modo que as "Check lists" de cada certificadora ficassem lado a lado em colunas.

A partir disso, utilizando a GlobalGap como modelo comparativo, alteramos a ordem das linhas de modo que em determinada linha, ao longo de todas as colunas, 0 conteúdo abordado fosse o mesmo.

Essa sistematização facilitou a escolha dos critérios que fossem mais condizentes com o propósito do presente trabalho, ou então, a formulação de um novo critério e, da mesma forma, facilitou a exclusão de alguns que, mesmo contido em mais de uma das “Check lists” era claramente um obstáculo para a aplicação do critério a ser criado.

\subsection{GLOBALGAP}

Fundada no ano de 1997, por 22 varejistas europeus conhecidos como Euro Retailers Produce Working Group (EUREP), a atualmente conhecida como "GLOBALG.A.P.", surgiu como resposta ao interesse dos consumidores em assuntos como segurança alimentar, normas ambientais e de trabalho.

A GlobalG.A.P. é hoje, uma organização privada que estabelece normas voluntárias para a certificação de produtos agrícolas e passou a elaborar um conjunto de normas de Boas Práticas Agrícolas (BPA) que inclui diferentes requerimentos para os diferentes produtos e que pode ser adaptada a toda agricultura mundial possibilitando 0 bem-estar dos trabalhadores e a Gestão Integrada das Culturas ${ }^{11}$.

Atualmente a dificuldade dos pequenos agricultores de se adequar às exigências da GlobalG.A.P. incentivou a elaboração de três diferentes abordagens para facilitar o acesso do pequeno agricultor ao mercado consumidor.

Entre elas, observamos a Certificação em Grupo (possibilita uma redução significativa das despesas externas de certificação, como taxas de inspeção, por exemplo), Manual para Pequenos Agricultores (ajuda os produtores a estabelecer os seus

\footnotetext{
${ }^{11}$ GLOBALGAP, 2007. Disponível em: <http://www.globalgap.org/cms/front_content.php?idcat=19> Acesso em 25 de maio de 2011.
} 


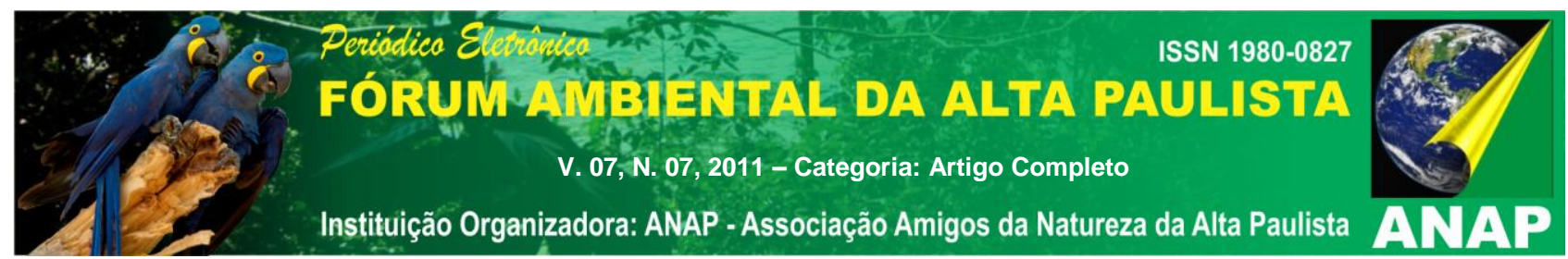

sistemas internos de controle) e Oportunidades de Reagir (espaço aberto às sugestões dos pequenos agricultores) $)^{12}$.

A GLOBALG.A.P. apresenta normas para diferentes setores: frutas e vegetais, flores ornamentais, aquacultura e café, além do integrated farm assurance (IFA), que inclui certificação em fazendas leiteiras, de carne bovina, ovina, suína, de frango e de $\operatorname{grãos}^{13}$.

No entanto, apesar de facilitar o acesso às cadeias de supermercados, a GlobalG.A.P. conta com um elevado número de procedimentos administrativos, e o custo da certificação pode ser elevado.

Além disso, o produtor não recebe nenhum sobre preço, ou Prêmio, como acontece, por exemplo, nas certificações do tipo Comércio Justo ${ }^{14}$.

\subsection{RAINFOREST ALLIANCE}

A Rainforest Alliance Certified surgiu no ano de 1986 nos Estados Unidos, na cidade de New York, no momento em que ambientalistas se reuniram com o objetivo de discutir o desaparecimento de florestas tropicais e de determinadas espécies ${ }^{15}$.

Com o intuito de buscar por mecanismos que trouxessem equilíbrio para as florestas, principalmente no que cerne produção e consumidor, surgiu em 1998, com a coalizão de organizações não-governamentais e RAINFOREST, a certificação socioambiental, a qual institui a Rede de Agricultura Sustentável - RAS ${ }^{16}$.

Esta certificação tem como foco fundamental demonstrar práticas sustentáveis para empresas com base na conservação ambiental e no desenvolvimento humano.

\footnotetext{
${ }^{12}$ GLOBAGAP - SMALLHOLDER INVOLVEMENT. Disponível em: <http://www.globalgap.org/cms/front_content.php?idcat=70> Acesso em 25 de maio de 2011.

${ }^{13}$ CERTIFICAÇÃO GLOBALGAP. Disponível em: <http://www.brcl.com.br/int_eurepgap_certificacao.asp> Acesso em 25 de maio de 2011.

${ }^{14}$ LAFORGA, EID; 2005

${ }^{15}$ RAINFOREST ALLIANCE TIMELINE. Disponível em: < http://www.rainforest-alliance.org/about/history> Acesso em 31 de maio de 2011.

${ }^{16}$ PALMIERI, R.H , 2008.
} 


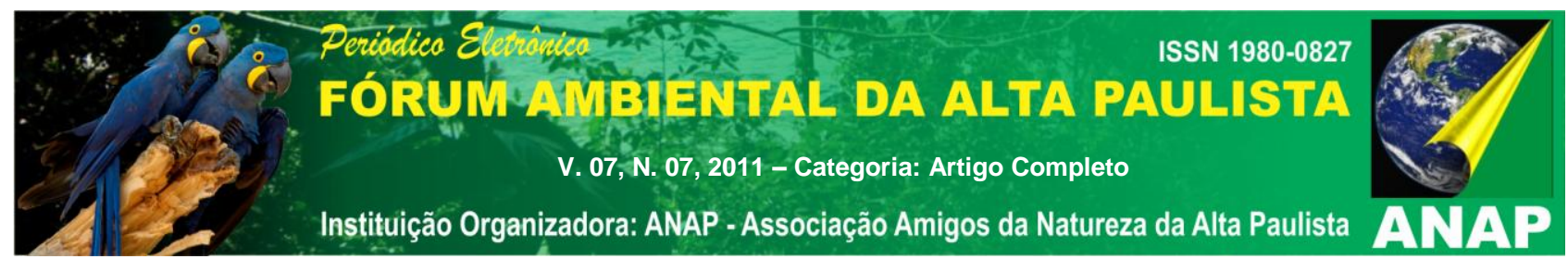

O selo Rainforest Alliance Certified é encontrado na Europa, Japão, Austrália, Nova Zelândia, Américas do Norte, Central e do Sul, além de estabelecimentos que ostentam tal selo, dentre os produtos certificados tem-se café, cacau, banana.

\subsection{FAIRTRADE}

A Fairtrade Labelling Organizations (FLO), originada na Holanda, teve seu primeiro produto, o café, certificado em $1989^{17}$.

Também conhecido como Comércio Justo, esse tipo de certificação teve como principal motivação, a inclusão de pequenos produtores, organizados em associações e cooperativas, no comércio mundial ${ }^{18}$.

Hoje, o Comércio Justo é baseado na transparência e proximidade entre produtores e consumidores, visando principalmente à inclusão de produtores familiares marginalizados no mercado e a melhoria das condições comerciais para os mesmos, possibilitando que o pequeno produtor obtenha um melhor preço por seus produtos.

No entanto, a quantidade de produtores certificados é limitada, e uma vez certificado, não há garantias de que o produto será vendido ${ }^{19}$.

\subsection{FELICIDADE INTERNA BRUTA- FIB}

O conceito Felicidade Interna Bruta (FIB) surgiu em 1972 como uma forma de questionar se o indicador Produto Interno Bruto (PIB), seria o melhor indicador para analisar o desenvolvimento de uma nação.

Dessa forma, o rei do Butão Jigme Singye Wangchuck criou a $\mathrm{FIB}^{20}$, sugerindo novos padrões de análise.

\footnotetext{
${ }^{17}$ CONSUMERS INTERNATIONAL, 2005

${ }^{18}$ PINTO; PRADA, 1999.

${ }^{19}$ LAFORGA, EID; 2005

${ }^{20}$ ALVES, SALCIDES, 2010.
} 


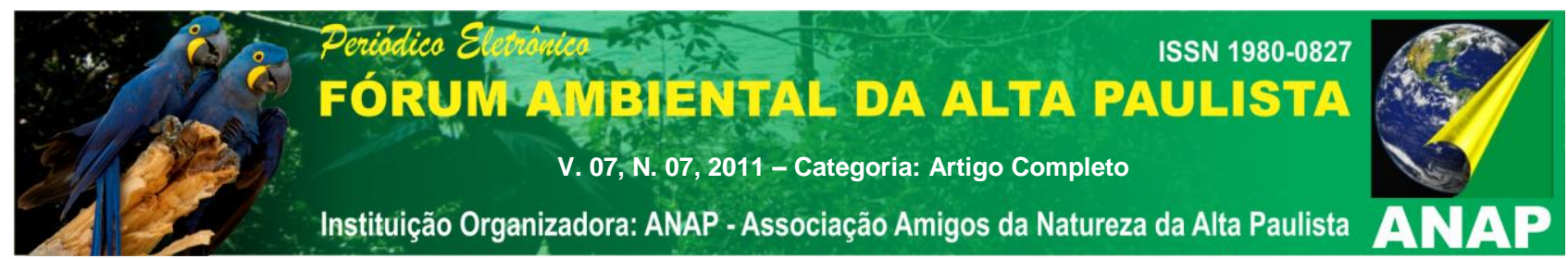

Neste indicador além de analisar as características econômicas do PIB, considerase outros aspectos como, a conservação do meio ambiente e a qualidade de vida dos habitantes.

O índice FIB permite que o governo reconheça os números por de trás dos indicadores e deste modo estabeleça um desenvolvimento integral.

O FIB é baseado em quatro pilares: economia, cultura, meio ambiente e boa governança, dos quais são derivados 09 domínios, com os quais são extraídos os indicadores para que a conceituação "felicidade" seja alcançada.

As principais categorias de avaliação são: bem-estar psicológico; meio ambiente; saúde; educação; cultura; padrão de vida; uso do tempo; vitalidade comunitária; e boa governança ${ }^{21}$.

\subsection{PRODUTO ORGÂNICO BRASIL}

No Brasil, a necessidade de regulamentação de produtos orgânicos surgiu com a Instrução Normativa n. 007 de 17 de maio de 1999, que dispõe sobre normas para a produção de produtos orgânicos vegetais e animais.

Esta norma foi criada quando da reunião de representantes e entidades ligadas a produção e consumo, com o propósito de estabelecer regras para a produção e comercialização de orgânicos em todo território nacional. A partir desta normativa foi criado o selo de qualidade para os produtos orgânicos ${ }^{22}$.

Com a normativa surgiram os Órgãos Colegiados, Nacional (OCN) e Estadual, que possuem como responsabilidade a função de credenciar as instituições certificadoras.

Outro marco no caminho da produção de alimentos orgânicos foi a edição da Lei n. 10.831, de 23 de dezembro de 2003, que dispõe sobre agricultura orgânica e dá outras providências.

\footnotetext{
${ }^{21}$ IBID., 2010.

${ }^{22}$ FONSECA, M.F. de A.C, 2009.
} 


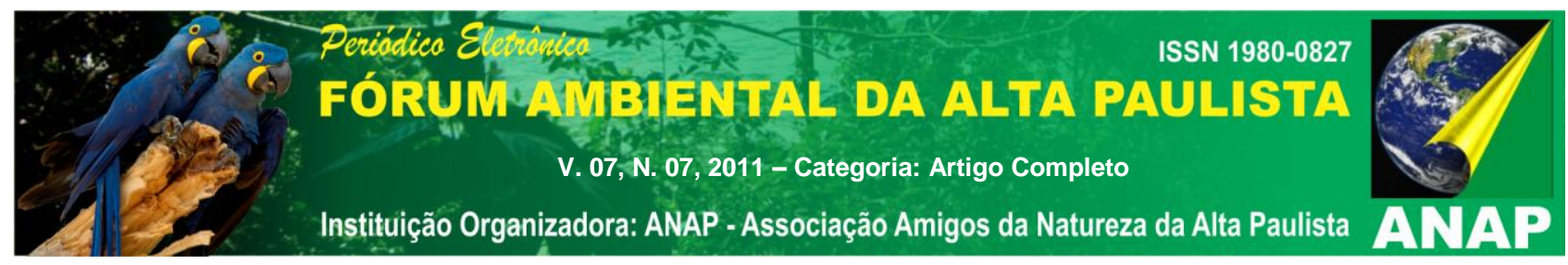

No artigo 1ำ, considera-se sistema de produção orgânica todo aquele onde são empregadas técnicas específicas, a fim de aperfeiçoar os recursos naturais e socioeconômicos ${ }^{23}$.

Dispõe, a referida lei, que o processo de certificação deve compreender a agricultura orgânica e todos os sistemas que promovam a sustentabilidade da produção dos alimentos, em caráter ambiental, social e econômico.

A maior dificuldade, tendo em vista que esta lei estabelece pormenorizadamente que um produto só pode ser vendido como orgânico se certificado por empresas reconhecidas oficialmente, é em adquirir a certificação cujo custo é relativamente elevado para pequenos produtores.

Sendo assim, é extremamente oportuna, conveniente e necessária, para os produtores, a certificação participativa, a vinculação de suas atividades e produtos a cooperativas ou instituições certificadoras que atendem as suas realidades socioeconômicas.

Deste modo, o produtor poderá obter o selo do Sistema Brasileiro de Avaliação da Conformidade Orgânica (SISOrg) e, para usufruto do selo, terá que estar condicionado à avaliação de conformidade do processo produtivo com as normas regulamentadas pelo Organismo de Avaliação da Conformidade (OAC), credenciado pelo Ministério da Agricultura, Pecuária e Abastecimento (MAPA).

\section{$3.6 \quad$ FSC}

Fundada em 1993, em Toronto, Canadá, com o propósito de promover o manejo responsável das florestas do mundo, a Forest Stewardship Council é uma organização não governamental, sem fins lucrativos, autoconceituada como uma alternativa para o impasse internacional nas políticas florestais, que conta com 126 participantes de 26 países $^{24}$.

\footnotetext{
${ }^{23}$ BRASIL. Lei n. 10.831, de 23 de dezembro de 2003. Dispõe sobre a agricultura orgânica e dá outras providências. Disponível em: <http://www.planalto.gov.br/ccivil_03/Leis/2003/L10.831.htm> Acesso em 1 de junho de 2011.
}

${ }^{24}$ PATTBERG, 2005. Disponível em: < http://www.fsc.org/about-fsc.html> Acesso em 26 de maio de 2011. 


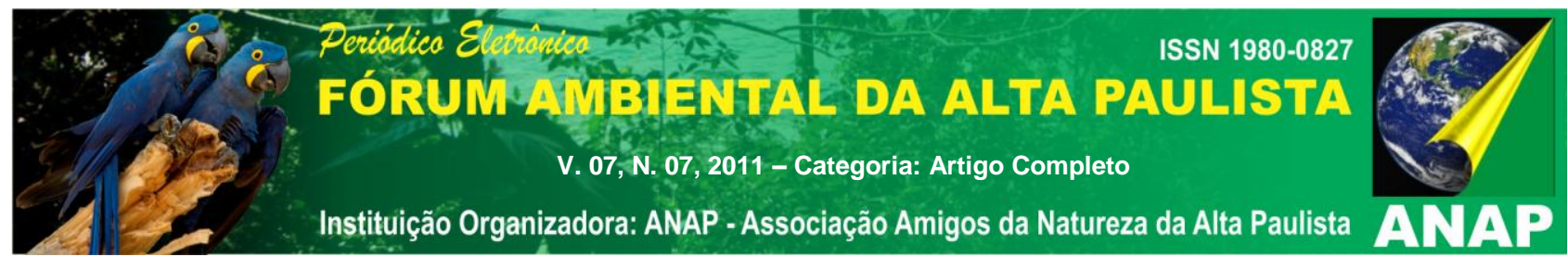

A organização em questão apresenta dois tipos de certificação: (i) Certificação do manejo florestal: são certificadas operações de manejo florestal que cumprem com os Princípios e Critérios do $\mathrm{FSC}^{25}$ e; (ii) Certificação de Cadeia de Custódia: no caso de produtos florestais transportados e processados por diferentes empresas, esse tipo de certificação garante que a matéria-prima é proveniente de florestas certificadas ${ }^{26}$.

Atualmente, existem 55 milhões de hectares de florestas no mundo que são certificadas pela FSC.

A Amazônia brasileira tem 1,13 milhão de hectares de florestas certificadas, a maior parte gerenciada por grandes empresas privadas ${ }^{27}$.

Os "Princípios e Critérios" exigidos pela FSC são considerados os mais rigorosos do mundo, no entanto, a organização vem sofrendo críticas devido a alguns estudos que revelaram impactos ecológicos em propriedades certificadas pela $\mathrm{FSC}^{28}$

Apesar disso, a exigência do mercado consumidor externo pela conservação florestal e manutenção da qualidade de vida prevalece, de modo que é esperado um aumento no número de empresas madeireiras certificadas no Brasil ${ }^{29}$.

\subsection{UTZKAPEH}

A UTZ KAPEH (bom café, na língua maia Quiché) é um modelo de certificação que surgiu da associação da empresa holandesa Ahold (grupo varejista europeu), com fornecedores da Guatemala no ano de 1997.

A razão para criação da UTZ certified foi originar reconhecimento para os produtores responsáveis por café e ferramentas para os torrefadores, e possibilitar que os mesmos respondessem a uma crescente demanda por produtos e matérias-primas de qualidade, que fossem produzidas de forma responsável ${ }^{30}$.

\footnotetext{
${ }^{25}$ IMAFLORA, 2002; ALVES R. $R$ et al, 2007

${ }^{26}$ NARDELLI \& TOMÉ; 2002.

${ }^{27}$ FSC, 2005; SOUZA, M. C. M. et al, 2006.

${ }^{28}$ COUNSELL \& LORAAS, 2002

${ }^{29}$ BRASIL, 1999; ALVES R. R. et al, 2007

${ }^{30}$ MARTINEZ, J. R. L. T, 2008.
} 


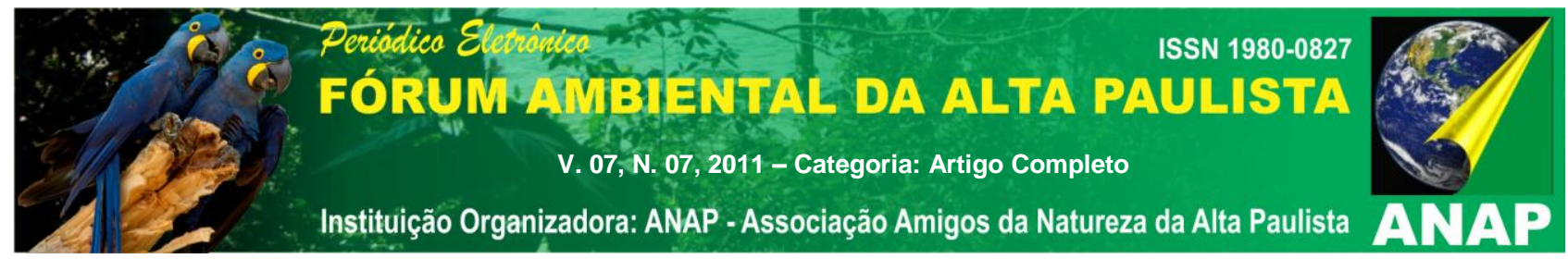

O foco da UTZ KAPEH além da produção com qualidade é a abordagem das condições de saúde e de trabalho dos funcionários, em conformidade com a legislação e a preocupação com a sustentabilidade social, ambiental e cultural dentro das empresas e nas comunidades do entorno ${ }^{31}$.

A certificação UTZ KAPEH é um conjunto de critérios internacionalmente reconhecidos que são semelhantes ao protocolo EUREPGAP de boas práticas agrícolas $^{32}$.

Os principais produtos certificados hoje são: café, cacau, chá e azeite de palma ${ }^{33}$.

\section{RESULTADOS E DISCUSSÃO}

Dentro da construção da proposta de um SIG-AF para pequenas propriedades rurais, o módulo "Associativismo e Comunidade" nada mai sé que o primeiro e principal aspecto para formalizar a criação de um protocolo de certificação sustentanvel.

Assim, tendo em vista o processo de leitura, análise, sistematização, discussão e compilação dos principais aspectos das normas foi possível elaborar a Tabela 01.

Tabela 01 - Módulo Associativismo e Comunidade (SIG-AF de pequenas propriedades rurais)

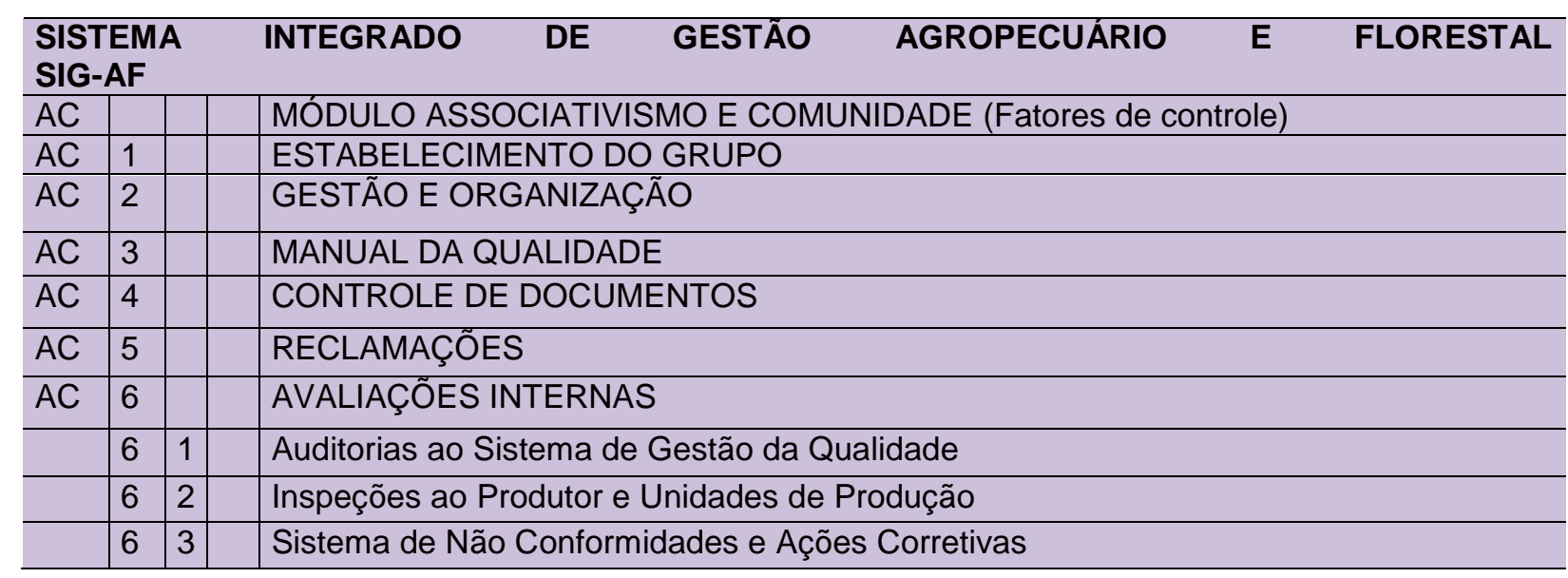

\footnotetext{
${ }^{31}$ UTZ. Disponível em: <http//www.utzcertified.com>

${ }^{32}$ SIQUEIRA, A. L, 2006.

${ }^{33}$ CARFANTAN, J.Y; BRUM, A.L, 2006.
} 


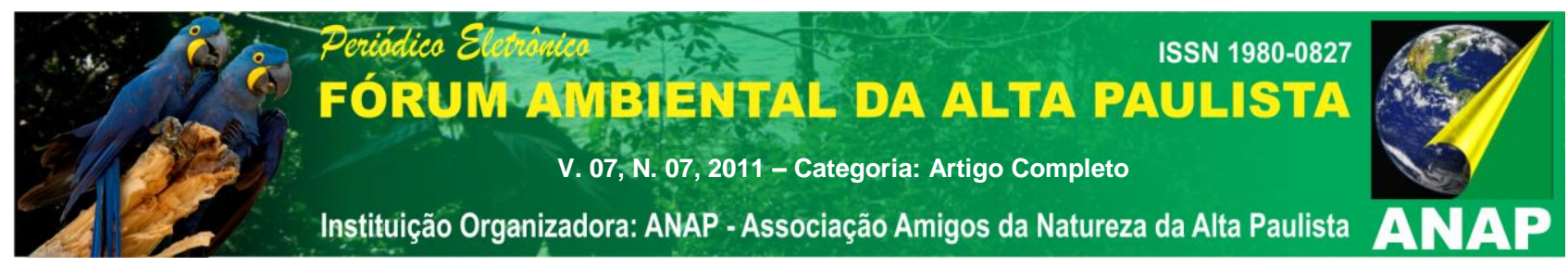

Na tabela acima, para estruturação do módulo "Associativismo e Comunidade", de um SIG-AF aplicado às pequenas propriedades rurais, foram estruturados 6 critérios primordiais a serem perseguidos, que serão complementados nos itens da Tabela 02.

Tabela 02 - Itens complementares do Módulo Associativismo e Comunidade (SIGAF de pequenas propriedades rurais)

\begin{tabular}{l|l|l|l|l}
\hline AC & 7 & & & RASTREABILIDADE E SEGREGAÇÃO DO PRODUTO \\
\hline AC & 8 & & & SANÇÕES E NÃO-CONFORMIDADE \\
\hline AC & 9 & & & RETIRADA DE PRODUTO CERTIFICADO \\
\hline AC & 10 & & & SUBCONTRATADOS \\
\hline AC & 11 & & & AVALIAÇÃO, PLANEJAMENTO E MONITORAMENTO DO IMPACTO \\
\hline & 11 & 1 & & Dimensão Educação \\
\hline & 11 & 2 & & Dimensão cultura \\
\hline & 11 & 3 & & Dimensão vitalidade comunitária \\
\hline & 11 & 4 & & Dimensão Boa Governança \\
\hline
\end{tabular}

Destes critérios devem ser destacados: Estabelecimento do Grupo; Gestão e Organização; Manual da Qualidade; Controle de Documentos; Reclamações; e Avaliações Internas ${ }^{34}$.

Por fim, com respeito ao objetivo básico do SIG-AF em questão, qual seja, estruturação de um módulo voltado para os escopos Associativismo e Comunidade adaptado às condições, peculiaridades, restrições e características das pequenas propriedades rurais, consoante disposto na Tabela 01, os seguintes elementos poderiam ser destacados de cada um destes principais critérios:

Estabelecimento do Grupo $\rightarrow$ Proposta de uma Assembleia Geral (AG) como elemento básico articular do SIG-AF;

Gestão e Organização $\rightarrow$ Organização de estatutos; registro individualizado de cada produtor; especificação de deveres e responsabilidades; e criação de um setor específico para a finalidade de avaliação da conformidade como mecanismo de gestão própria;

Manual da Qualidade, Controle de Documentos e Reclamações $\rightarrow$ Tratam-se de elementos imprescindíveis em todo e qualquer SIG e/ou protocolo de certificação;

\footnotetext{
${ }^{34}$ Os demais critérios seriam: Rastreabilidade e Segregação do Produto; Sanções e Não-conformidade; Retirada do Produto Certificado; Subcontratados; e Avaliação, Planejamento e Monitoramento do Impacto.
} 


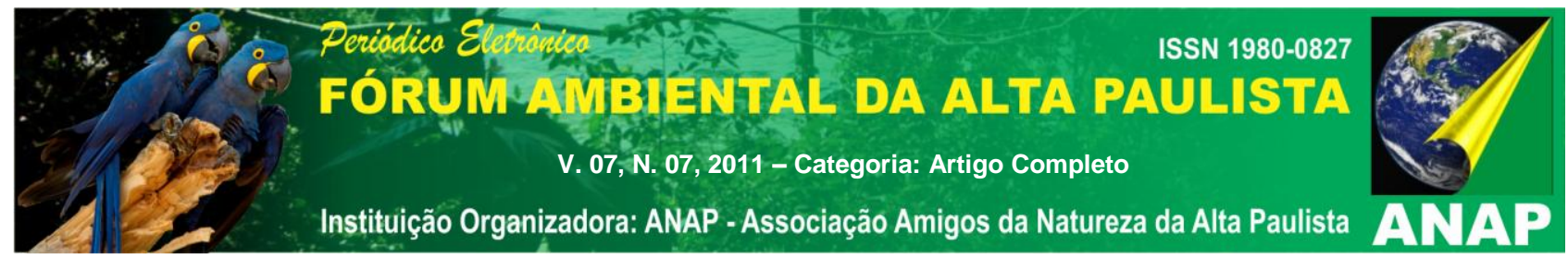

Avaliações Internas $\rightarrow$ Propostas em bases de avaliação colaborativa com a finalidade da adaptabilidade e conformidade de um SIG tipicamente focado em pequenas propriedades rurais.

\section{CONCLUSÕES}

A atual, acentuada e crescente proeminência da pequena propriedade rural enseja que também ela seja imperiosamente inserida dentro das mais modernas e sustentáveis práticas agrícolas. Dentro deste escopo, a criação de m SIG-AF voltado para pequenas propriedades rurais é questão primordial.

A criação de um SIG-AF para pequenas propriedades rurais, e mesmo de um futuro e eventual protocolo de certificação, contudo, deve certamente considerar peculiaridades, características, limitações e fragilidades típicas.

Para tanto, a primeira etapa a ser vencida é o Módulo Associativismo e Comunidade para a sustentação de um protocolo de certificação sustentável e/ou SIG-AF para pequenas propriedades rurais.

A construção do Módulo Associativismo e Comunidade, dentro de um SIG-AF de pequenas propriedades rurais deve considerar, dentre outros critérios ambientais, os sub módulos: Estabelecimento do Grupo; Gestão e Organização; Manual da Qualidade; Controle de Documentos; Reclamações; e Avaliações Internas.

Destes sub módulos, os principais aspectos que devem caracterizar um protocolo de certificação sustentável e/ou um SIG-AF para pequenas propriedades rurais seriam: Assembléia Geral; organização de estatutos; registro individualizado de cada produtor; especificação de deveres e responsabilidades; e criação de um setor específico para finalidade de avaliação da conformidade como mecanismo de gestão própria.

Naturalmente que aspectos tais como "Manual da Qualidade", "Controle de Documentos" e "Reclamações" não podem ser deixados à margem de um protocolo de certificação sustentável e/ou SIG-AF para pequenas propriedades rurais.

Por fim, em termos do desenvolvimento de um primeiro módulo (qual seja, Associativismo e Comunidade), o sub módulo "Avaliações Internas" deve ser estruturado 


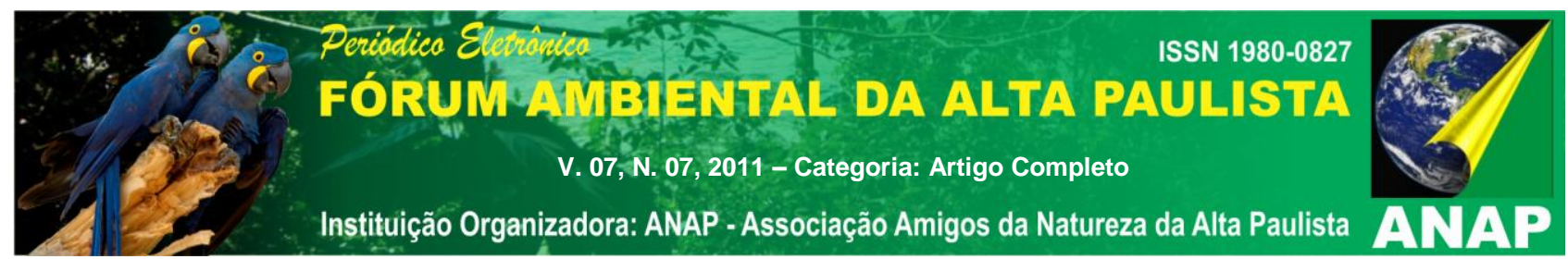

em bases de avaliação colaborativa com a finalidade da adaptabilidade e conformidade de um SIG tipicamente focado em pequenas propriedades rurais.

Uma vez elaborada uma primeira proposta, consoante os termos aqui dispostos, a próxima etapa seria, então, o desenvolvimento dos critérios de cumprimento dos fatores de controle apresentados no trabalho.

Ademais, será necessária a realização de um teste piloto em algumas propriedades rurais para efeitos de estudo e aprimoramento do protocolo de certificação sustentável e/ou SIG-AF.

\section{REFERÊNCIAS}

ALVES FILHO, E.; SALCIDES, A. M. F. (2010) Is it possible to be happy after imposed migration? Resettlers of the President JK Power Plant, Brazil. In: XVII ISA WORLD CONGRESS OF SOCIOLOGY, Gothenburg.

ALVES, R. R., JACOVINE, L. A. G., SILVA, M. L., VALVERDE, S. R. (2007) Certificação florestal na visão gerencial e estratégica do polo moveleiro de Ubá, MG. Cerne, Lavras, v. 13, n. 1, p. 117-122.

BRASIL. Lei n. 10.831, de 23 de dezembro de 2003. Disponível em: <http://www.planalto.gov.br/ccivil_03/Leis/2003/L10.831.htm> Acesso em 1 de junho de 2011.

BRASIL. Ministério do Meio Ambiente. Estado da arte da certificação florestal. Brasília, DF, 1999. p. 25

CARFANTAN, J.Y; BRUM, A.L. (2006) O Agronegócio brasileiro e as novas regras de acesso ao mercado da união europeia. Desenvolvimento em Questão, julho-dezembro, ano/vol.4, número 008 - Universidade Regional do Noroeste do Estado do Rio grande do Sul, Brasil pp. 119-157. 
CONSUMERS INTERNATIONAL - From bean to cup: how consumer choice impacts on coffee producers and the environment ISBN - 1-902391-63-2 Published by Consumers International in December 2005.

FONSECA, M. F. de A. C.; SOUZA, C. de; SILVA, G. R. R.; COLNAGO, N. F.; BARBOSA, S. C. A. (2009) Agricultura orgânica: regulamentos técnicos e acesso aos mercados dos produtos orgânicos no Brasil. 1a ed. Niterói: PESAGRO-RIO, v. 01. 119 p.

FOREST STEWARDSHIP COUNCIL - FSC. Banco de Dados. Disponível em: $<w w w . f s c . o r g>$. Acesso em 10 de Junho de 2011.

GLOBALGAP. CERTIFICAÇÃO GLOBALGAP. Disponível em: <http://www.brcl.com.br/int_eurepgap_certificacao.asp> Acesso em 25 de maio de 2011.

LAFORGA, G.; EID, F. (2005) Certificação Social: Potencialidades Do Comércio Justo Para A Agricultura Familiar Brasileira. In: XLIII CONGRESSO DA SOBER, 2005, RIBEIRÃO PRETO. ANAIS DO XLIII CONGRESSO DA SOBER. RIBEIRÃO PRETO : USP, v. 1.

MARTINEZ, J. R. L. T.; JESUS, J. C. S.; COCARO, H. (2008) Casos sobre a certificação Utz Kapeh em empresas cafeeiras informatizadas: impactos nas pessoas, gestão e competitividade. In: SOBER (XLVI Congresso da Sociedade Brasileira de Economia, Administração e Sociologia Rural, ACRE. SOBER (XLVI Congresso da Sociedade Brasileira de Economia, Administração e Sociologia Rural).

NARDELLI, A. M. B.; TOMÉ, M. V. D. F. (2002) Efeito multiplicador dos benefícios da certificação florestal. Revista Floresta, Curitiba, p. 94-98. Edição Especial.

PALMIERI, R. H. (2008) Impactos socioambientais da certificação Rainforest Alliance em fazendas produtoras de café no Brasil. Dissertação de mestrado em ecologia 


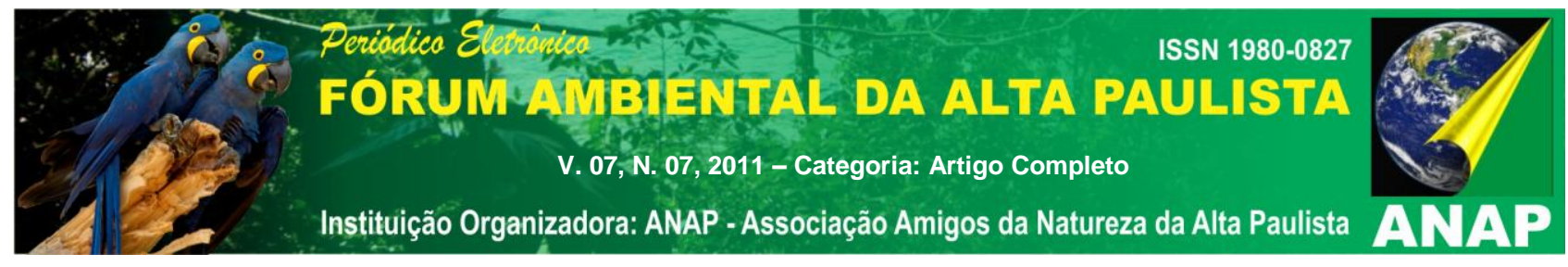

aplicada, Universidade de São Paulo, Escola Superior de agricultura "Luiz Queiroz" Centro de Energia Nuclear na Agricultura, Piracicaba/SP.

PATTBERG, P. (2005) What Role for Private Rule-Making in Global Environmental Governance? Analysing the Forest Stewardship Council (FSC). International Environmental Agreements 5:175-189. Berlin.

PINTO, L.F.G.; PRADA, L. de S. (1999) Certificação Agrícola Socioambiental: iniciativa piloto para cana-de-açúcar. Informações Econômicas, São Paulo, v.29, n.5, p. 20-29.

RAINFOREST ALLIANCE TIMELINE. Disponível em: < http://www.rainforestalliance.org/about/history> Acesso em 31 de maio de 2011.

SIQUEIRA, A. L.; OLIVEIRA, F. V.; MATOS, M. A.; SCHENINI, P. C. (2006) A certificação como instrumento de verificação de práticas sustentáveis na produção do café. In: $1^{\circ}$ Seminário sobre Sustentabilidade - UNIFAE, 2006, Curitiba. Anais do 1ำ Seminário sobre Sustentabilidade - UNIFAE.

SOUZA, M. C. M.; DRIGO, I. G.; PIKETTY, M. G. (2006) Certificação do café orgânico e da madeira no Brasil: um caminho para a sustentabilidade? Informações Econômicas, SP, v.36, n.11.

UTZ KAPEH FOUNDATION. Disponível em: <http://www.utzcertified.org/> Acesso em 10 de junho de 2011. 